\title{
Reuna
}

\section{O FATOR SUSTENTABILIDADE NAS LICITAÇÕES E CONTRATAÇÕES PÚBLICAS}

\author{
THE FACTOR SUSTAINABILITY IN BIDDING AND PUBLIC PROCUREMENT
}

http://dx.doi.org/10.21714/2179-8834/2016v21n4p37-56

\author{
Cristiano Ferreira Costa \\ Universidade Federal de Viçosa, Brasil. \\ Endereço: Av. P. H. Rolfs, s/n, Centro, CEP 36570000 - Vicosa, MG - Brasil \\ Fone: +55 (31) 38992455 \\ Email: cristiano_ufv@yahoo.com.br - Lattes: http://lattes.cnpq.br/8581506232045131 \\ Maria de Fátima Santos Diniz \\ Universidade Federal de Viçosa, Brasil. \\ Endereço: Av. P. H. Rolfs, s/n, Centro, CEP 36570000 - Vicosa, MG - Brasil \\ Fone:+55 (31) 38992455 \\ Email: mfsdiniz@ufv.br - Lattes: http://lattes.cnpq.br/0203556454190293 \\ Nina Rosa da Silveira Cunha \\ Universidade Federal de Viçosa, Brasil. \\ Endereço: Av. P. H. Rolfs, s/n, Centro, CEP 36570000 - Vicosa, MG - Brasil \\ Fone: +55(31) 38992455 \\ Email: ninarosa@ufv.br - Lattes: http://lattes.cnpq.br/3142635757586338

\section{Ruthe Rebello Pires} \\ Universidade Federal de Minas Gerais, Brasil. \\ Endereço: Avenida Antônio Carlos, 6627, Pampulha CEP 31270-901 - Belo Horizonte, MG - Brasil \\ Fone: +55(31) 34097247 \\ Email: rutheprof@gmail.com - Lattes: http://lattes.cnpq.br/5905824932563379
}

Submissão: 14 Jul. 2015 Publicação: 31 Dez. 2016. Sistema de avaliação: Double blind review. Centro Universitário UNA, Belo Horizonte - MG, Brasil. Editor geral Prof. Dr. Mário Teixeira Reis Neto

Este artigo encontra-se disponível no endereço eletrônico:

Reuna: http://revistas.una.br/index.php/reuna/article/view/793

DOI - http://dx.doi.org/10.21714/2179-8834/2016v21n4p37-56

\section{Resumo}

A pesquisa trata de licitações sustentáveis, do desenvolvimento sustentável e o papel do poder público na realização de contratos e compras com respeito ao meio ambiente. São estudadas as dificuldades no estabelecimento de parâmetros de sustentabilidade ambiental nas propostas de licitação, os critérios que devem ser elencados para aferir a sua sustentabilidade, em especial no setor de construção civil, os benefícios econômicos e sociais, e as justificativas legais e econômicas. Como pesquisa exploratória, o método foi $\mathrm{o}$ de consultas bibliográficas e documentais. Percebeu-se que, em alguns casos, a Administração Pública não está preparada para realizar procedimentos licitatórios sustentáveis, em razão da sua deficiência em identificar, na fase de planejamento, o impacto ambiental do objeto a ser executado. Não obstante, a pesquisa revelou que a preocupação ambiental tende a gerar maiores benefícios econômicos, mormente na construção civil com o uso racional de materiais e com redução da pressão na utilização irracional dos 
recursos naturais. Há como conciliar interesses econômicos com a consciência ambiental. A importância do poder público em induzir transformações no mercado com intervenção na economia por força das compras e contratos é crucial para que as licitações sustentáveis sejam vistas como forma eficiente de investimento na sustentabilidade. Sugere-se que a Administração Pública, ainda que na ausência de critérios ambientais de julgamento de propostas fixadas por Lei, elabore parâmetros exigindo do particular nos certames licitatórios, a realização de condutas ou a adoção de práticas sustentáveis compatíveis com o objeto licitado.

Palavras-chave: desenvolvimento sustentável, impacto ambiental, licitações sustentáveis, contratações públicas, construção civil.

\section{Abstract}

The research deals with sustainable procurement, sustainable development and the role of government in the realization of contracts and purchases with respect to the environment. the difficulties in establishing environmental sustainability parameters in bidding proposals are studied, the criteria to be listed to assess their sustainability, particularly in the construction sector, the economic and social benefits, and the legal and economic justifications. As exploratory research, the method was the bibliographical and documentary consultations. It was noticed in some cases that the Public Administration is not prepared to make sustainable bidding procedures, on the basis of disability to identify, in the planning stage, the environmental impact of the object to be executed. Nevertheless, the survey revealed that environmental concern tends to generate greater economic benefits, especially in construction to the rational use of materials and reducing the pressure on the irrational use of natural resources. There is how to reconcile economic interests with environmental awareness. The importance of government to induce changes in the market with intervention in the economy by virtue of purchases and contracts is crucial for sustainable procurement are seen as an efficient way of investing in sustainability. It is suggested that the Government, even in the absence of environmental criteria for judging proposals laid down by law, work parameters requiring the particular in bidding contests, conducting ducts or the adoption of sustainable practices compatible with the object.

Keywords: sustainable development, environmental impact, sustainable procurement, public procurement, civil construction.

\section{Introdução}

O desenvolvimento sustentável começa a ser tratado já no preâmbulo da Constituição Federal (BRASIL, 1988), com a afirmação de que a sua promulgação foi destinada a assegurar o desenvolvimento como um dos seus valores supremos.

Para garantir o desenvolvimento nacional sustentável, é necessário promover licitações sustentáveis. Conforme previsto no art. 225 da Constituição Federal de 1988, as licitações sustentáveis estão inseridas no cerne do direito fundamental ao meio ambiente ecologicamente equilibrado, tendo o Poder Público bem como a coletividade a sua defesa e a sua preservação para as gerações presentes e futuras (BRASIL, 1988). Além disso, a licitação sustentável permite regras e condições para incorporar aspectos de proteção e conservação ambiental no processo de seleção da melhor proposta feita à Administração Pública, levando-se em consideração que existem impactos ambientais gerados na compra de materiais e realização de obras 
públicas, que devem ser controlados de forma que se permita também, o respeito ao princípio administrativo da supremacia do interesse público (TORRES, 2012).

A Lei $n$ ㅇ 12.462, de 4 de agosto de 2011, que institui o Regime Diferenciado de Contratações Públicas (RDC) e em seu artigo $3^{\circ}$ estabeleceu a promoção do desenvolvimento nacional como um de seus princípios.

Inicialmente destinava-se a agilizar os processos licitatórios das obras para os Jogos Olímpicos e Paraolímpicos de 2016, Jogos da Copa das Confederações de 2013, Jogos de Copa do Mundo de 2014 e de obras de infraestrutura e de contratação de serviços para os aeroportos das capitais dos Estados da Federação distantes até $350 \mathrm{~km}$ das cidades sedes dos mundiais. Mais tarde, também serviram para os processos licitatórios das ações do Programa de Aceleração do Crescimento (PAC), obras e serviços de engenharia no âmbito do Sistema Único de Saúde (SUS), obras de engenharia para construção, ampliação e reforma de estabelecimentos penais. Em seu artigo 4으, estabelece como diretriz, especificamente no inciso III, a "busca da maior vantagem para a administração pública, considerando custos e benefícios, diretos e indiretos, de natureza econômica, social ou ambiental, inclusive os relativos à manutenção, ao desfazimento de bens e resíduos, ao índice de depreciação econômica e a outros fatores de igual relevância".

Faz-se premente que os processos licitatórios sustentáveis garantam o meio ambiente ecologicamente equilibrado, de modo a não gerar impactos ambientais com externalidades negativas, em obras no uso de recursos ambientais.

Em relação ao emprego do fator de sustentabilidade nas licitações, a questão que se coloca para investigação é: os critérios utilizados pela legislação brasileira para o julgamento de uma proposta são ou não são sustentáveis e como na prática a legislação brasileira vem tratando este tema? É evidente que a consideração de fatores de sustentabilidade é de importância crucial para promoção, manutenção e defesa dos interesses públicos em relação à conservação e proteção do meio ambiente e a sua interação com aspectos econômicos e sociais, pois servem para evitar ou minimizar passivos ambientais decorrentes do objeto a ser licitado.

Do ponto de vista teórico e prático, espera-se que haja contribuição com este estudo, para o entendimento da necessidade de criação de critérios para aferir a sustentabilidade de uma proposta, o que é de crescente relevância para as organizações e a sociedade, considerando-se os benefícios econômicos e sociais, examinando-se se o maior custo gerado por especificações de natureza sustentável é justificável legal e economicamente. Evitar e minimizar os problemas ambientais são formas de economizar o dinheiro público, ainda, de modo que a população e o ambiente não tenham que conviver com seus malefícios.

O foco do estudo foi voltado para a área de construção civil pelo fato de que tal área é potencialmente causadora de impactos ambientais significativos e em relação à qual é fácil entender que os benefícios ambientais de critérios de sustentabilidade aplicados em objetos de licitação, como obras de engenharia, podem estar ligados a vantagens que vão além da defesa e promoção do meio ambiente, alcançando benefícios econômicos, como o uso racional de recursos naturais e materiais.

Nesse contexto, o objetivo geral deste estudo é o de examinar o papel do fator sustentabilidade nas licitações e contratos públicos, em especial no setor de construção civil, face a legislação. 


\section{Desenvolvimento sustentável e a legislação brasileira}

O termo desenvolvimento sustentável originou-se da "necessidade de se conciliar o desenvolvimento econômico e a preservação do meio ambiente" (SOARES; NAVARRO; FERREIRA, 2004), e surgiu nos anos 1980, a partir do termo ecodesenvolvimento, criado na década anterior. Os dois termos passaram a ser tratados como sinônimos, sendo que o termo desenvolvimento sustentável prevaleceu como de uso mais comum, principalmente após ser divulgado na Conferência Rio 92 (PEREIRA; CURI, 2012).

O desenvolvimento sustentável refere-se a uma forma de permitir que a sociedade humana global continue a promover a melhoria de sua qualidade de vida através das atividades econômicas, com geração de riquezas, distribuição de renda e justiça social, sem que o meio ambiente seja comprometido de forma que coloque em risco a manutenção dos padrões ambientais que permitem uma vida saudável para as pessoas, e com respeito à conservação dos recursos naturais para resguardar as gerações presentes e futuras em relação ao provimento de suas necessidades e promoção de seu bem estar (ASSOCIATION FRANÇAISE DE NORMALISATION - AFNOR, 2003; BARBIERI et al., 2010; BLOWFIELD, 2013; DEACON, 1998; FISHER, 1981; OLIVEIRA et al., 2010); PEERMAN et al., 1999; REDCLIFT, 1992; SACHS,2007; TIETENBERG, 2016; VEIGA, 2005; WORLD COMISSION ON ENVIROMENMENT AND DEVELOPMENT, 1988).

O papel do Estado para a promoção da sustentabilidade é muito importante. Pelas normas legislativas o Estado gera mudanças no comportamento de empresas e pessoas, criando regras de conduta para a promoção da sustentabilidade e meios de regulação das atividades que geram impacto ambiental. Ele pode incentivar que empresas tomem postura proativa na proteção e conservação do meio ambiente, com incentivos fiscais, por exemplo. O Estado pode ainda criar sanções sobre quem age de forma a degradar o meio ambiente, contra a exploração predatória dos recursos naturais, contra a poluição do solo, da água ou do ar.

A lei da Política Nacional de Meio Ambiente (Lei 6.938/81), a lei da Ação Civil Pública (Lei 7.347/85) e a Constituição Federal, de 1988, estabeleceram princípios e políticas ambientais. A Constituição Federal dedica um capítulo inteiro à proteção do meio ambiente (Capítulo VI - Do Meio Ambiente), e no seu todo, possui 37 artigos relacionados ao direito ambiental. O texto constitucional estabeleceu uma série de obrigações em relação à preservação e recuperação de ecossistemas, à preservação do patrimônio genético, à educação ambiental, à definição de áreas a serem protegidas e à exigência de estudos de impacto ambiental para instalação de atividade econômica que tenha o potencial de causar degradação ao meio ambiente.

A Lei no 6938 de 1981 instituiu a Política Nacional do Meio Ambiente, estabelecendo os princípios da regulamentação ambiental e os conceitos do direito ambiental, meio ambiente, degradação, recursos naturais e poluidor. Tem como objetivo a compatibilização do desenvolvimento econômico e social com a preservação da qualidade do meio ambiente e do equilíbrio ecológico (BRASIL, 2010, p. 15).

A Lei da Ação Civil Pública (Lei no 7.347/85), ao tutelar os direitos difusos e coletivos, regulamentou as ações de responsabilidade por dano causado ao meio ambiente e ao consumidor (BRASIL, 2010, p. 15). 
O Estado, com a criação de políticas públicas de cunho ambiental, de leis ambientais, e ao conferir um viés ambiental em leis das mais diversas áreas, como na área de Licitações e Contratos, por exemplo, é indutor de transformações econômicas, sociais, culturais e de comportamento que podem multiplicar efeitos benéficos sobre a conservação e proteção do meio ambiente. Portanto, o Estado tem papel crucial no fortalecimento da sustentabilidade.

\section{Impacto ambiental}

O impacto ambiental é conceituado pela legislação brasileira na resolução CONAMA no 1 de 1986, como:

[...] qualquer alteração das propriedades físicas, químicas e biológicas do meio ambiente, causada por qualquer forma de matéria ou energia resultante das atividades humanas que, direta ou indiretamente, afetam: a saúde, a segurança e o bem-estar da população; as atividades sociais e econômicas; as condições estéticas e sanitárias do meio ambiente; e a qualidade dos recursos ambientais.

O impacto ambiental seria o resultado da própria existência humana, a qual demanda ação e reação na natureza, do desenvolvimento embrionário até a decomposição ou destruição do corpo humano. É possível pensar que a todo momento gera-se impacto no ambiente, seja pela necessidade de suprir, através dos alimentos, o gasto de energia pelo nosso corpo; pela interação que se mantem com a microbiota, já que o corpo humano possui número de bactérias superior ao número de células; pelo consumo de oxigênio e geração de gás carbônico pela respiração pulmonar; e da própria presença, que ao ocupar espaço, modifica o ambiente.

Porém, o termo impacto ambiental é mais empregado em relação aos efeitos de atividades humanas que afetam o ambiente em grande escala, influindo sistematicamente nas condições de vida de um grupo grande de pessoas, na vida dos animais e das plantas de uma determinada região ou lugar e nos padrões de qualidade dos recursos ambientais.

De forma sucinta, "o impacto ambiental pode ser conceituado como sendo a alteração da qualidade ambiental que resulta na modificação de processos naturais ou sociais provocadas por ação humana" (SÁNCHEZ, 2008, p. 32).

No caso da construção civil, toda nova edificação produz impactos, sejam ambientais sociais ou econômicos. É preciso considerar que grandes mudanças ocasionadas pela construção civil interferem na sociedade devido à implantação de novas edificações. Algumas medidas podem ser tomadas para evitar ou minimizar os impactos gerados por construções. Por exemplo, reutilizar materiais novos que causem menor impacto ambiental ou organizar o canteiro de obras para que as quantidades dos resíduos da construção sejam menores e não tenham grande impacto, considerando-se que os materiais da construção civil não são renováveis.

\footnotetext{
"Os impactos provocados por obras de construção civil podem criar alguns transtornos para as pessoas que moram ou transitam na região, porém as alterações provocadas não serão sempre negativas, uma vez que podem gerar benefícios ao entorno. Por isso, deve-se sempre levar em consideração a opinião da sociedade quanto a alterações provocadas por obras da construção civil" (SPADOTTO et al., 2011, p. 173).
} 
Para a identificação dos impactos ambientais associados a determinado empreendimento, deve-se procurar selecionar todas as atividades, produtos e serviços relacionados à atividade produtiva, de modo a distinguir o maior número possível de impactos ambientais gerados, reais e potenciais, benéficos e adversos, decorrentes de cada aspecto identificado, sempre considerando se tais impactos são significativos ou não (BACCI; LANDIM; ESTON, 2006).

A Resolução CONAMA 307/2002 estabelece diretrizes, critérios e procedimentos para a gestão dos resíduos da construção civil. Especifica os aspectos ambientais e seus respectivos impactos, a frequência e a probabilidade de ocorrências desses aspectos, a severidade dos impactos e caracteriza os tipos de resíduos da construção civil: sólidos (sobras de concreto, lajes, tijolos, ...), químicos (aditivos de concreto, agrotóxicos, ...), recursos naturais renováveis ou não (água, energia elétrica, óleo diesel, ...), emissão atmosférica (gases de combustão, poeira, material particulado, ...), efluentes líquidos (contaminação com óleo, efluente sanitário, lavação de veículos peças, ...), resíduos líquidos (sobras de tintas e solventes, vazamento de óleo de BPF/xisto/diesel, ...), risco ambiental (derramamento de produto químico, de óleo diesel, lubrificante, incêndio, explosão, ...). Ainda, provenientes da construção, demolição, reformas, reparos e da preparação e escavação do solo (BACCI; LANDIM; ESTON, 2006).

Observa-se o zelo da legislação na conservação dos recursos naturais, considerando que a construção demanda o uso de grande quantidade de recursos renováveis e não renováveis, como os energéticos, renováveis, hídricos e territoriais. Mas, parte dos resíduos gerados na construção civil é deixada clandestinamente em terrenos baldios, várzeas e taludes de cursos d'água, ocasionando impactos ao meio ambiente e causando transtornos ao trânsito de veículos e pedestres. Quando os resíduos não são removidos pelo poder público, isso faz com que o local acabe sendo destino de outros tipos de lixo (poda de árvores, móveis, pneus e, eventualmente, resíduos domiciliares). O acúmulo destes resíduos pode provocar contaminação e proliferação de animais e insetos transmissores de doenças. Os resíduos, ao serem levados pelas águas, obstruem as canalizações de drenagem. Como a maioria dos municípios não possui áreas destinadas à recepção destes resíduos, estes são, em geral, depositados em áreas de importantes cursos d'água, causando enchentes e trazendo prejuízos para a sociedade (KÜSTER et al., 2007).

\section{Licitação sustentável}

Durante séculos os atores governamentais e autoridades públicas não consideravam o impacto dos produtos que compravam, dos serviços que contratavam e das obras que empreendiam. Com o surgimento do conceito de desenvolvimento sustentável no cenário político mundial, observa-se a tendência da geração de políticas que levam em conta os aspectos ambientais, que geralmente comprometem também os aspectos sociais e econômicos (BRASIL, 2010, p. 8).

A Lei 8.666 de 1993, que institui normas para as licitações e contratos da administração pública brasileira, diz em seu artigo $3^{\circ}$ que:

A licitação destina-se a garantir a observância do princípio constitucional da isonomia, a seleção da proposta mais vantajosa para a administração e a promoção do desenvolvimento nacional sustentável e será processada e julgada em estrita conformidade com os princípios básicos da legalidade, da impessoalidade, da moralidade, da igualdade, da publicidade, da probidade 
administrativa, da vinculação ao instrumento convocatório, do julgamento objetivo e dos que Ihes são correlatos.

Esse artigo passou a fazer referência à licitação sustentável com o acréscimo da palavra sustentável ao termo desenvolvimento nacional, a partir da sua nova redação dada pela Lei Federal 12.349 de 2010. Assim, a legislação passa a vincular a licitação à sua sustentabilidade, e a partir de então se pode falar em licitação sustentável.

\begin{abstract}
É necessário introduzir parâmetros de sustentabilidade, sem frustrar a competitividade ou promover discriminações entre os potenciais interessados no processo licitatório. Por conseguinte, as licitações públicas nacionais passam a considerar critérios de sustentabilidade ambiental (VALENTE, 2011, p. 10).
\end{abstract}

Nesse sentido, e tendo em vista o amadurecimento da sociedade brasileira para as questões ambientais, atualmente existem instrumentos de comando e controle no ordenamento jurídico brasileiro, direcionados ao desenvolvimento sustentável. Especificamente, em relação à inclusão de critérios de sustentabilidade nas compras públicas, o Ministério do Planejamento, Orçamento e Gestão (MPOG) e os Governos Locais pela Sustentabilidade (ICLEI), citam em seu "Guia de Compras Públicas Sustentáveis para Administração Federal” os seguintes instrumentos de comando e controle no ordenamento jurídico brasileiro (BRASIL, 2010, p. 16):

- A resolução CONAMA n 20 , de 1994, que dispõe sobre a instituição do selo ruído, de uso obrigatório para aparelhos eletrodomésticos que geram ruído no seu funcionamento;

- O Decreto ํㅡ 2.783/98, que proíbe o governo federal de comprar produtos ou equipamentos contendo substâncias degradadoras da camada de ozônio;

- O Decreto no 4.131/02, que dispõe sobre medidas emergenciais de redução do consumo de energia elétrica no âmbito da Administração Pública Federal.

- A Resolução CONAMA n 307, de 2002, que estabelece critérios e procedimentos para gestão de resíduos na construção civil - a Portaria no 43 do Ministério do Meio Ambiente, que proíbe o uso do amianto em obras públicas e veículos de todos os órgãos vinculados à administração pública;

- A Portaria n 61 do Ministério do Meio Ambiente, que estabelece práticas de sustentabilidade ambiental quando das compras públicas sustentáveis;

- A Instrução normativa no 01 de 19 de janeiro de 2010, que dispõe sobre critérios de sustentabilidade ambiental na aquisição de bens, contratação de serviços ou obras pela administração pública direta, autárquica e fundacional.

No Guia é possível encontrar as formas como a Administração Pública deve exercer compra ou contratação de um serviço para contemplar a sustentabilidade, de maneira que não causem danos ao meio ambiente (degradação); de forma que seja utilizada a menor quantidade possível de recursos naturais e que a maior quantidade possível de produtos seja reutilizada, reaproveitada ou reciclada; e adotando critérios de sustentabilidade ambiental, englobando os processos de extração ou fabricação, utilização e descarte dos produtos e matérias-primas.

O Ministério do Planejamento, Orçamento e Gestão, pela Secretaria de Logística e Tecnologia da Informação, criou a Instrução Normativa no 1, de 19 de janeiro 2010, com a finalidade de dispor sobre os critérios de sustentabilidade 
ambiental na aquisição de bens, contratação de serviços ou obras pela Administração Pública Federal direta, autárquica e fundacional:

O instrumento normativo infere um olhar mais detalhado aos critérios
ambientais. Estes não poderão ser utilizados como forma de frustrar a
competitividade, ratificando o princípio da isonomia entre os licitantes
estabelecido na lei geral de licitações. É importante que haja clareza na
exposição do critério ambiental, o peso de cada critério deve ser indicado e
previamente calculado em relação aos demais critérios do produto/serviço,
de forma que este não se constitua em um critério eliminatório quando não
for essencial à finalidade da contratação.
[...] Neste sentido, como ressaltamos acima, os critérios de sustentabilidade
ambiental devem ser delimitados de forma objetiva, clara e precisa. A
exigência de certificação, por exemplo, pode ser um critério, desde que não
fira este princípio do julgamento objetivo e da isonomia, pilares dos
procedimentos de concorrência pública e que, diante sua inexistência, não
cause a eliminação do concorrente por não possuía-la.
Grande parte da normativa rege as obras públicas sustentáveis e
estabelece obrigações relativas à gestão ambiental adequada, e
sustentável, da obra a ser contratada (BRASIL, 2010, p. 22).

A licitação sustentável permite regras e condições para incorporar aspectos de proteção e conservação ambiental no processo de seleção da melhor proposta feita à Administração Pública, levando-se em consideração que existem impactos ambientais gerados na compra de materiais e realização de obras públicas, e devem ser controlados de forma que se permita também, o respeito ao princípio administrativo da supremacia do interesse público.

\section{Metodologia}

O presente trabalho classifica-se quanto aos fins como exploratória e quanto aos meios como bibliográfica e documental (VERGARA, 2010). Para Marconi e Lakatos (2007) a pesquisa exploratória é a primeira aproximação de um tema e visa criar maior familiaridade em relação a um fato ou fenômeno. Os métodos exploratórios empregados são o levantamento bibliográfico em livros, periódicos, revistas técnicas, visitas a websites, etc., e a análise documental. A pesquisa documental utiliza-se de material mais diversificado que pode ser coletado em instituições.

Como procedimento técnico, realizou-se inicialmente levantamento bibliográfico, buscando-se na ordem jurídica brasileira, principalmente na legislação relativa às licitações e contratos, parâmetros objetivos para se verificar, na prática, se uma proposta é ou não é sustentável. Para tanto, investigaram-se as principais leis e normas ambientais relacionadas ao objeto de estudo e os mais importantes instrumentos regulatórios, identificando a evolução histórica e características atuais. Finalmente, com base na revisão da literatura, examinaram-se os critérios de sustentabilidade ambiental, presentes na Instrução Normativa no 1, de 19 de janeiro de 2010 da Secretaria de Logística e Tecnologia da Informação, do Ministério do Planejamento, Orçamento e Gestão (MPOG), que é a responsável pelo portal eletrônico de contratações públicas do Governo Federal - Comprasnet.

O material coletado foi organizado segundo critérios de análise de conteúdo, utilizando-se a técnica de apontamento. Dessa ação elaborou-se o Quadro 1, 
sintetizando os tipos de materiais coletados, seguindo a cronologia das publicações, que fundamenta o capítulo analítico.

Quadro 1: Banco de dados do material coletado para fundamentação analítica

\begin{tabular}{|c|c|c|}
\hline Título & Caracterização do material & Caracterização do conteúdo \\
\hline $\begin{array}{l}\text { Lei Federal oㅇ } 8.666 \text { de } 21 \\
\text { de junho de } 1993 .\end{array}$ & Lei geral de licitações no Brasil. & $\begin{array}{l}\text { Institui normas para licitações e } \\
\text { contratos da Adm. Pública. }\end{array}$ \\
\hline $\begin{array}{l}\text { Lei Federal } n^{\circ} 10.257 \text {, de } \\
\text { Julho de } 2001 .\end{array}$ & Estatuto da cidade. & Estuda o impacto de vizinhança. \\
\hline $\begin{array}{l}\text { Guia de compras públicas } \\
\text { sustentáveis: uso do poder } \\
\text { de compra do governo para } \\
\text { a promoção do } \\
\text { desenvolvimento sustentável } \\
\text { (2006). }\end{array}$ & $\begin{array}{l}\text { Publicação das instituições ICLEI } \\
\text { - Governos Locais pela } \\
\text { Sustentabilidade, Secretariado } \\
\text { para América Latina e Caribe } \\
\text { (LACS) e Centro de Estudos em } \\
\text { Sustentabilidade da Esc. de Adm. } \\
\text { Empr. S.Paulo da Fund.Getúlio } \\
\text { Vargas. }\end{array}$ & $\begin{array}{l}\text { Apresenta experiências a } \\
\text { respeito de licitações } \\
\text { sustentáveis em diferentes } \\
\text { países. }\end{array}$ \\
\hline $\begin{array}{l}\text { Guia de compras públicas } \\
\text { sustentáveis (2010). }\end{array}$ & $\begin{array}{l}\text { Publicação do Ministério do } \\
\text { Planejamento, Orçamento e } \\
\text { Gestão e Governos Locais pela } \\
\text { Sustentabilidade (ICLEI). }\end{array}$ & $\begin{array}{l}\text { Descreve as características das } \\
\text { licitações sustentáveis. }\end{array}$ \\
\hline $\begin{array}{l}\text { Instrução Normativa no } 1 \text {, de } \\
19 \text { de janeiro de } 2010 .\end{array}$ & $\begin{array}{l}\text { Documento da Secretaria de } \\
\text { Logística e Tecnologia da } \\
\text { Informação, do Ministério do } \\
\text { Planejamento, Orçamento e } \\
\text { Gestão (MPOG). }\end{array}$ & $\begin{array}{l}\text { Critérios de sustentabilidade para } \\
\text { realização de editais de licitações } \\
\text { sustentáveis para aquisição } \\
\text { bens, contratação de serviços ou } \\
\text { obras pela Adm. Pública Federal } \\
\text { direta, autárquica e fundacional, } \\
\text { o julgamento das propostas e } \\
\text { para identificar os benefícios } \\
\text { econômicos e sociais para as } \\
\text { organizações que utilizam a } \\
\text { licitação sustentável. }\end{array}$ \\
\hline $\begin{array}{l}\text { Avaliação de custos e } \\
\text { benefícios ambientais } \\
\text { (2011). }\end{array}$ & $\begin{array}{l}\text { Publicação da Escola Nacional de } \\
\text { Administração Pública - ENAP. }\end{array}$ & $\begin{array}{l}\text { Descreve os tipos de custos, } \\
\text { relacionando-os ao meio } \\
\text { ambiente, e seus benefícios } \\
\text { sociais e econômicos. }\end{array}$ \\
\hline $\begin{array}{l}\text { Decreto } 7.581 \text { de } 11 \text { de } \\
\text { outubro de } 2011 .\end{array}$ & $\begin{array}{l}\text { Decreto de regulamentação do } \\
\text { Regime Diferenciado de } \\
\text { Contratações Públicas - RDC, de } \\
\text { que trata a Lei no } 12.462 \text { de } 4 \text { de } \\
\text { agosto de } 2011 .\end{array}$ & $\begin{array}{l}\text { Determina a possibilidade de } \\
\text { utilização de parâmetros de } \\
\text { sustentabilidade ambiental p/ } \\
\text { pontuar propostas técnicas e } \\
\text { propostas na licitação para } \\
\text { contratação de projetos. Permite } \\
\text { que o instrumento convocatório } \\
\text { estabeleça pontos mínimos, } \\
\text { podendo a proposta ser } \\
\text { desclassificada. }\end{array}$ \\
\hline $\begin{array}{l}\text { Marco legal das licitações e } \\
\text { compras sustentáveis na } \\
\text { Adm. Pública (2011). }\end{array}$ & $\begin{array}{l}\text { Publicação da Câmara dos } \\
\text { Deputados. }\end{array}$ & $\begin{array}{l}\text { Aborda a legalidade das } \\
\text { licitações sustentáveis. }\end{array}$ \\
\hline $\begin{array}{l}\text { Promoção da } \\
\text { sustentabilidade nas } \\
\text { organizações incluindo } \\
\text { critérios sustentáveis nas } \\
\text { compras (2014). }\end{array}$ & $\begin{array}{l}\text { Artigo apresentado no Congresso } \\
\text { Internacional de Administração, } \\
\text { Ponta Grossa, } 22 \text { a } 26 \text { de set. de } \\
2014 \text {. }\end{array}$ & $\begin{array}{l}\text { Trata sobre considerações e } \\
\text { descrições sobre compras } \\
\text { sustentáveis. }\end{array}$ \\
\hline
\end{tabular}

Fonte: Elaborado pelos autores 
A decisão da escolha por estas fontes de informações justifica-se pelo esforço requerido de uma pesquisa e em razão das inúmeras dificuldades em identificar os critérios uniformes acerca da sustentabilidade para todas as formas de contratação pública e, em especial, para a área de construção civil. Ainda, pelo fato de que tal área é potencialmente causadora de impactos ambientais significativos e em relação à qual é fácil entender que os benefícios ambientais de critérios de sustentabilidade aplicados em objetos de licitação, como obras de engenharia, podem estar ligados a vantagens que vão além da defesa e promoção do meio ambiente, alcançando benefícios econômicos, como por exemplo, pelo uso racional de recursos naturais e materiais, de acordo com o que foi constatado durante o levantamento bibliográfico.

\section{Resultados}

Analisou-se o papel do fator sustentabilidade nas licitações e contratos públicos, abordando as dificuldades no estabelecimento de parâmetros de sustentabilidade ambiental nas propostas de licitação, e em especial no setor de construção civil, os critérios que devem ser elencados para aferir a sustentabilidade de uma licitação; os benefícios econômicos e sociais para as organizações que utilizam a licitação sustentável. Buscou-se também examinar se o maior custo gerado por especificações de natureza sustentável é justificável legal e economicamente; ainda, as formas específicas de alguns países tratarem a licitação sustentável.

\subsection{Dificuldades no estabelecimento de parâmetros de sustentabilidade ambiental nas propostas de licitação}

O Decreto 7.581 de 2011, que regulamenta o Regime Diferenciado de Contratações Públicas, determina que poderão ser utilizados parâmetros de sustentabilidade ambiental para pontuação das propostas técnicas e das propostas na licitação para contratação de projetos. Permite ainda que o instrumento convocatório estabeleça pontuação mínima, abaixo da qual a proposta pode ser desclassificada.

Contudo, uma análise mais aprofundada do decreto revela que a dificuldade de se ter descrição pormenorizada dos parâmetros de sustentabilidade a serem utilizados, é supostamente decorrente da enorme variedade de parâmetros que podem ser adotados de acordo com cada tipo de objeto, aliado ao fato de que este tema ainda é recente para ser tratado com tanta riqueza de detalhes na legislação.

Daí parte-se para a ideia de parâmetros mínimos estabelecidos pela legislação. Como norma do ato administrativo, compreende-se que a adoção de um determinado parâmetro de sustentabilidade deve ser justificada pela Administração.

Cada órgão público pode adotar diferentes parâmetros de acordo com cada objeto a ser licitado, desde que sejam bem fundamentados. Tal fundamentação seria estritamente de ordem técnica, considerando-se o conhecimento econômico, sociológico e ecológico acerca das influências e consequências do objeto da licitação para o ambiente como um todo. 


\subsection{Critérios para aferir sustentabilidade de uma licitação na construção civil}

A Secretaria de Logística e Tecnologia da Informação, do Ministério do Planejamento, Orçamento e Gestão (MPOG), responsável pelo portal eletrônico de contratações públicas do Governo Federal - Comprasnet, criou a Instrução Normativa no 1 (IN), em 2010, com a finalidade de dispor sobre os critérios de sustentabilidade ambiental na aquisição de bens, contratação de serviços ou obras pela Administração Pública Federal direta, autárquica e fundacional. Na construção civil existem diversos parâmetros de sustentabilidade relacionados às obras de construção de estradas, pontes, edifícios, etc., com especificidades típicas.

Em seu artigo 4을 determina que, de acordo com o artigo 12 da Lei 8.666 de 1.993, as especificações e demais exigências do projeto básico ou executivo, para contratação de obras e serviços de engenharia pela Administração Pública, devem ser elaboradas visando à economia da manutenção e operacionalização da edificação, a redução do consumo de energia e água, bem como a utilização de tecnologias e materiais que reduzam o impacto ambiental, como uso de equipamentos de climatização mecânica, ou de novas tecnologias de resfriamento do ar, que utilizem energia elétrica, apenas nos ambientes aonde for indispensável, automação da iluminação do prédio, uso exclusivo de lâmpadas fluorescentes compactas ou tubulares de alto rendimento, energia solar, sistema de medição individualizado de consumo de água e energia, de reuso de água, dentre outros.

A partir da análise da IN № 1, verifica-se que a legislação não apresenta parâmetros objetivos para se determinar a sustentabilidade em relação a uma proposta na licitação, porque a legislação foi feita preocupando-se com a formulação do objeto a ser licitado. Todas as empresas dispostas a participar da disputa pela elaboração e/ou execução de um projeto de engenharia do setor da construção civil, terão que observar o que é disposto pela legislação sobre parâmetros de sustentabilidade. A Administração Pública fica responsável por anunciar o que considera que seja feito na obra, para que sejam respeitados os parâmetros de sustentabilidade, uma vez que o projeto a ser elaborado será vinculado ao Projeto Básico, elaborado pela Administração Pública, observando as disposições da IN nº 1, de 19 de janeiro de 2010, para licitar obra ou serviço de engenharia.

Ainda, pelo artigo $2^{\circ}$ da IN o instrumento convocatório deverá formular as exigências de natureza ambiental de forma a não frustrar a competição. Porém, de acordo com o artigo $3^{\circ}$ da mesma IN, determinou-se que nas licitações que usem como critério de julgamento a melhor técnica ou técnica e preço, os critérios objetivos de sustentabilidade ambiental para a avaliação e classificação das propostas deverão ser estabelecidos no edital da licitação.

Assim sendo, observa-se que a responsabilidade da definição dos parâmetros de sustentabilidade a serem observados numa proposta, é da competência do órgão demandante do objeto, por ser ele quem formula o edital de licitação.

Uma obra de construção civil a ser executada implica em diferentes fatores limitantes e de interação que são fruto da variabilidade ambiental que se observa em ecossistemas diferentes, realidades socioeconômicas distintas e peculiaridades de locais específicos. Partindo desse raciocínio, compreende-se que muitas vezes será necessário que sejam realizados estudos técnicos que apontem quais parâmetros deverão ser enfatizados em cada caso, como na construção de uma estrada. A definição de projeto básico pela Lei 8.666 de 1.993, no seu artigo 6º, item IX, que evidencia a discricionariedade da Administração em determinar esses parâmetros, é: 
Conjunto de elementos necessários e suficientes, com nível de precisão adequado, para caracterizar a obra ou serviço, ou complexo de obras ou serviços objeto da licitação, elaborado com base nas indicações dos estudos técnicos preliminares, que assegurem a viabilidade técnica e o adequado tratamento do impacto ambiental do empreendimento, e que possibilite a avaliação do custo da obra e a definição dos métodos e do prazo de execução.

Os parâmetros de sustentabilidade a serem observados para executar obras ou serviços no setor de construção civil em nome da Administração Pública, relacionados pela Instrução Normativa oㅡ 1, de 19 de janeiro de 2010, do MPOG, são básicos e servem de diretrizes, porém, podem ser melhorados de acordo com a necessidade de cada órgão público e de cada obra ou serviço pendente de execução. Todavia, deduz-se que é imprescindível a observância de toda a legislação ambiental e dos regulamentos que regem a licitação no que se refere à conservação e proteção do meio ambiente, para a composição do Projeto Básico de Engenharia e do Edital de Licitação.

Com o estudo de impacto de vizinhança, permite-se que sejam evitados problemas que aparecem sem nunca terem sido considerados em momento anterior e que podem ser tão graves ao ponto de ser possível se chegar à conclusão de que a obra não deveria ter sido realizada (pelo menos, não da mesma forma). Os passivos ambientais de uma obra de construção civil podem gerar consequências econômicas e sociais extrínsecas que não justificam a resolução do problema inicial a partir do qual se idealiza a execução da obra.

Verifica-se que a licitação será sustentável desde que o objeto seja sustentável, ou seja, a obra ou serviço a ser contratado ou o produto a ser adquirido, deve possuir características de execução ou produção que contemplem o necessário planejamento para a conservação e proteção ambiental. Além disso, os critérios de julgamento de propostas referentes à licitação do tipo melhor técnica ou técnica e preço, permitem incrementos de sustentabilidade que podem variar de acordo com a concorrência entre as empresas, de forma que o objeto a ser licitado seja executado o mais próximo possível da forma ideal de como deveria ser para elevar ao máximo o respeito e o cuidado com o meio ambiente.

\subsection{Benefícios econômicos e sociais para as organizações que utilizam a licitação sustentável}

As compras governamentais no Brasil movimentam cerca de $10 \%$ do PIB. $\mathrm{O}$ impacto econômico causado pelas contratações e compras realizadas pelo governo e seu evidente poder de indução do mercado constituem fatores chave para a implementação de compras públicas (licitações) sustentáveis (BRASIL, 2010).

Com a promoção de licitações sustentáveis, os órgãos públicos fazem com que a preservação e a conservação do meio ambiente sejam respeitadas pelas empresas licitantes, fornecedoras de produtos e serviços. Pela valorização da sustentabilidade, toda a cadeia produtiva e consumidora é influenciada de forma que haja a adaptação dos produtos e serviços à consciência ambiental. $O$ diferencial de melhor desempenho ambiental pode contar não só na preferência de quem compra o produto ou serviço, mas também economicamente de forma direta, considerandose que o uso racional de recursos naturais gera menos desperdício e maior eficiência. A empresa se reorganiza para melhorar a forma como impacta o meio REUNA, Bela Horizonte - MG, Brasil, v.21, n.4, p.37-56, Dut. - Dez. 20I6 - ISSN 2179-8834 
ambiente precisando alterar processos que impactam a sua eficiência e produtividade.

Ao contrário do que normalmente se imagina, as licitações sustentáveis não levam a compras mais caras, porque priorizam eficiência e redução de desperdício, o que resulta em economia para quem compra (BRASIL, 2010). Portanto, percebese que as licitações sustentáveis fazem com que os órgãos públicos promovam o uso mais eficiente dos recursos públicos, assegurando a manutenção da qualidade do ambiente, o que gera benefícios para toda a sociedade. Tais benefícios podem ser observados, por exemplo, na saúde, pela redução da poluição; em maior retorno dos impostos na forma de bens e serviços, gerando maior qualidade de vida para a população; na proteção do meio ambiente, permitindo que as gerações presentes e futuras tenham assegurado o direito de um meio ambiente ecologicamente equilibrado, com disponibilização de recursos naturais de forma satisfatória.

De acordo com Romeiro e Maia (2011), a metodologia de mercado de bens substitutos parte do princípio de que a perda de qualidade ou escassez do bem ou serviço ambiental irá aumentar a procura por substitutos, na tentativa de manter o mesmo nível de bem-estar da população. As técnicas derivadas do mercado de bens substitutos, bastante conhecidas e de fácil aplicação, são custos evitados, custos de controle, custos de reposição e custos de oportunidade:

Custos evitados:

São muito utilizados em estudos de mortalidade e morbidade humana. $O$ método estima o valor de um recurso ambiental por meio dos gastos com atividades defensivas substitutas ou complementares, que podem ser consideradas uma aproximação monetária sobre as mudanças desses atributos ambientais. Por exemplo, quando uma pessoa paga para ter acesso à água encanada, ou compra água mineral em supermercados, supõe-se que esteja avaliando todos os possíveis males da água poluída, e indiretamente valorando sua disposição a pagar pela água descontaminada. [...]

Custos de controle:

Representam os gastos necessários para evitar a variação do bem ambiental e garantir a qualidade dos benefícios gerados à população. É o caso do tratamento de esgoto para evitar a poluição dos rios e um sistema de controle de emissão de poluentes de uma indústria para evitar a contaminação da atmosfera. [...]

Custo de reposição:

Com esse método, a estimativa dos benefícios gerados por um recurso ambiental será dada pelos gastos necessários para reposição ou reparação após esse recurso ser danificado. É o caso do reflorestamento em áreas desmatadas e da fertilização para manutenção da produtividade agrícola em áreas onde o solo foi degradado. [...]

Custo de Oportunidade:

[...] Toda conservação traz consigo um custo de oportunidade das atividades econômicas que poderiam estar sendo desenvolvidas na área de proteção, representando, assim, as perdas econômicas da população em virtude das restrições de uso dos recursos ambientais. Em um parque ou reserva florestal com exploração restringida, o custo de oportunidade de sua preservação seria dado pelos benefícios de uma possível atividade de exploração de madeira (ROMEIRO e MAIA, 2011, p. 43-47).

Com base na análise dos custos e benefícios relacionados às licitações sustentáveis, é proposto um conjunto de especificações listadas no Quadro 2. 
Quadro 2: Custos e benefícios

\begin{tabular}{lll}
\hline Custos & Benefícios sociais & Benefícios econômicos \\
Evitados & Saúde pública & Redução dos custos hospitalares \\
de controle & Bem estar da população & Redução do desperdício de materiais \\
de reposição & Serviços públicos & Redução virtual de impostos \\
de oportunidade & Proteção da sociedade & Redução de despesas \\
\hline
\end{tabular}
Fonte: Adaptado de Romeiro e Maia (2011).

Os custos sobre licitações sustentáveis no que se refere ao aumento de custo gerado por especificações de sustentabilidade podem gerar efeitos diversos dependendo de cada caso. Porém, por uma linha de raciocínio em que se procurou identificar possíveis benefícios sociais e econômicos em relação a cada espécie de custo, foi composto o Quadro 2.

Com licitações sustentáveis incorpora-se ao objeto a ser licitado, especificações que têm a função de assegurar o cuidado com a saúde da população, como no caso do amianto, que pode causar câncer de pulmão. As pessoas que entrarem em contato com a obra sem amianto, por exemplo, não estarão sujeitas aos perigos desse material, simplesmente pela sua ausência. Processos de fabricação e construção podem conter componentes que afetam a saúde das pessoas, seja no entorno de um canteiro de obras ou pela natureza das matérias-primas utilizadas. A forma como uma obra de construção civil será conduzida, no que diz respeito ao planejamento para minimizar o estresse para a população do entorno, traz diferenças significativas para a saúde pública (momentos de descanso, de sono, alterações no trânsito, entre outros). Protegendo a saúde da população, reduz-se o número de internações, reduzindo custos hospitalares e de saúde pública.

A partir de especificações que permitem controle dos efeitos sobre o meio ambiente, é possível assegurar a manutenção das características ambientais que afetam a qualidade de vida das pessoas. Com o controle do efeito de uma obra sobre a qualidade do ar e da água, por exemplo, é possível promover o bem estar social. Com maior controle da relação entre as atividades de uma obra de construção civil e a sua geração de resíduos, os materiais tendem a ser utilizados de forma mais racional, gerando efeitos econômicos positivos com a redução de desperdícios.

A licitação de uma obra de construção civil pode exigir, por exemplo, que haja o controle da qualidade da água, monitorando-se propriedades físico-químicas e biológicas a montante e a jusante de um curso d'água na área de influência da obra, para que por comparação dos resultados encontrados, fique comprovado que a obra não está alterando a qualidade da água. Na construção de uma estrada, por exemplo, pode haver a exigência de uso de caminhão pipa para molhar o terreno durante as atividades de terraplanagem, evitando-se que seja gerada muita poeira.

Se uma especificação de natureza sustentável ajuda a evitar custos de reposição, pode-se pensar que haja prevenção contra gastos que seriam necessários para resolver os problemas por danos ambientais. Dessa forma, os recursos públicos poderão ser empregados em melhoria dos serviços públicos ao invés de serem empregados em obras reparadoras. 
Os custos de oportunidade são entendidos como o que se deixa de ganhar quando se reserva uma área para a conservação e proteção ambiental ao invés de explorála economicamente. Em relação às licitações sustentáveis, observa-se que o custo de oportunidade seria o que se deixa de economizar de forma direta ao se gastar mais com uma especificação de natureza ambiental. É importante descrever que a incorporação de especificações de sustentabilidade a um objeto de licitação transcende o valor econômico, pois afeta o meio ambiente e gera consequências sociais. O custo de oportunidade nesse caso, não deve ser concebido de forma direta e simples. Ele permite que se esteja pagando por meios de se evitar problemas geradores de despesas e prejuízos que vão muito além do seu valor monetário. Observa-se que o custo de oportunidade em relação a licitações sustentáveis é um modo de proteger a sociedade e de se evitar custos indiretos que no final das contas tornaria a despesa muito maior.

As licitações sustentáveis melhoram a imagem das autoridades públicas, pois se demonstra, que os gestores públicos são ambiental, social e economicamente responsáveis (BRASIL, 2010). São mais uma forma de se promover a sustentabilidade, porém, com papel crucial do poder público, que atua diretamente. Nesse caso, o poder público não age só como regularizador ou fiscalizador, mas como personagem central em cenário de transformação da realidade econômica, ambiental e social, a partir da concepção do interesse público em minimizar os efeitos da ação humana sobre as condições físicas e biológicas do planeta.

\subsection{Examinar se o maior custo gerado por especificações de natureza sustentável é justificável legal e economicamente}

As licitações sustentáveis podem conter especificações referentes a produtos e serviços que geram maior custo. Em alguns casos, uma especificação de natureza sustentável poderá gerar menor custo, mas quando o custo gerado é maior, é natural que se questione a necessidade de se pagar mais caro.

Observa-se que se o maior custo gerado for muito alto, o resultado da licitação poderá ser tornar economicamente inviável, porque por mais que se tente proteger e conservar o meio ambiente, ainda é preciso avaliar o grau de satisfação em suprir as demandas geradas pela sociedade com o uso eficiente dos recursos públicos. Portanto, torna-se necessário balancear o maior custo da licitação com especificações de natureza sustentável com a viabilidade econômica e o interesse público, sem deixar de promover a observância das leis licitatórias.

Quando o maior custo gerado por especificações de natureza sustentável sobre o objeto fornecer incrementos discretos de preço, é muito fácil perceber que a variação do custo se torna bem parecida com o que acontece em relação a diferentes conjuntos de especificações comuns, sem a abordagem da sustentabilidade. Nesse caso, os conjuntos diferentes de especificações podem ser avaliados como fonte de qualidades distintas para o suprimento das necessidades a que se prestam. A partir desse raciocínio, verifica-se que objetos que contém especificações de natureza sustentável possuem qualidade ambiental. Mesmo que haja um maior custo inicial, a população estará sendo beneficiada com serviços e produtos de acordo com o desenvolvimento sustentável. Em longo prazo, a disposição de se pagar mais caro por especificações de natureza sustentável, revela-se como um modo racional de prevenção em relação a problemas que podem 
trazer prejuízos que superam demasiadamente o valor a mais que pode ser pago para se ter produtos e serviços com qualidade ambiental.

Portanto, as licitações sustentáveis demonstram-se justificáveis economicamente, mesmo que inicialmente, os custos gerados por essa modalidade de licitação sejam maiores. É importante considerar também, que à medida que as empresas incorporem as especificações sustentáveis a competição entre elas fará com que sejam desenvolvidos e adotados novos processos e novas tecnologias que se destinam a solucionar os problemas de aspecto ambiental com custos menores. Os aumentos de preço por conta de especificações de natureza sustentável sobre o objeto tendem a se tornarem cada vez mais discretos, podendo até chegar ao ponto em que não haverá diferença significativa de preço.

Em relação à legalidade em 2010, as licitações sustentáveis se consolidaram fortemente. O Ministério do Planejamento, Orçamento e Gestão, através da sua Secretaria de Logística e Tecnologia da Informação, adotou a instrução normativa no 1 , de 19 de janeiro de 2010, a qual estabelece critérios de sustentabilidade ambiental na aquisição de bens e contratação de serviços ou obras na Administração Pública Federal. A instrução normativa passou a figurar como o primeiro marco regulatório para a adoção de critérios de sustentabilidade ambiental na esfera do governo federal, no que se refere a licitações sustentáveis. Valente (2011, p. 9) aponta as justificativas de legalidade das licitações sustentáveis:

[...] o artigo 170 da Constituição Federal determina que a ordem econômica observe 'a defesa do meio ambiente, inclusive mediante tratamento diferenciado conforme o impacto ambiental dos produtos e serviços e de seus processos de elaboração e prestação'.

O caput do art. 225 do texto constitucional impõe ao Poder Público o dever de defender e preservar o meio ambiente para as presentes e futuras gerações. [...]

[...] Em síntese, em função da interpretação dos arts. 23, VI, 37, XXI, 170, VI, e 225 da Constituição Federal, a Administração Pública deve procurar compatibilizar os bens e serviços a serem contratados com exigências relativas à proteção do meio ambiente. [...]

[...] Ainda no ano de 2010, o Congresso Nacional, ao deliberar sobre projeto de lei da conversão de medida provisória, acabou por instituir o marco legal das licitações sustentáveis no âmbito da Administração Pública brasileira. Essa importante inovação legal, promovida pela redação conferida ao art. $3^{\circ}$, caput, da Lei $n^{\circ}$ 8.666, de 21 de junho de 1993, pela Lei no 12.349, de 15 de dezembro de 2010, modifica radicalmente o quadro jurídico e operacional das licitações públicas no Brasil, obrigando todos os entes da Federação a promoverem licitações públicas sustentáveis.

A partir destas informações e ponderações, observa-se que as licitações sustentáveis são justificáveis legal e economicamente.

\subsection{Experiências de outros países: sugestões para a realidade brasileira}

Em 2005, a Organização das Nações Unidas (ONU), por meio do Departamento de Questões Ambientais e Sociais), realizou o $3^{\circ}$ Encontro de Especialistas sobre Licitação Pública Sustentável, com cerca de 60 especialistas de 23 países para discussão (Quadro 3) sobre compras públicas sustentáveis, considerando suas experiências (BIDERMAN et al., 2006, p. 71). 
Quadro 3: Experiências de licitação sustentável

\begin{tabular}{|c|c|}
\hline País & Algumas experiências sobre licitação sustentável \\
\hline $\begin{array}{l}\text { Estados } \\
\text { Unidos }\end{array}$ & $\begin{array}{l}\text { Incentivos fiscais para o uso de equipamentos eficientes ambiental e energeticamente; } \\
\text { Adoção de requisitos legais de construção e arquitetura sustentável; } \\
\text { Economia obrigatória de energia nos prédios. }\end{array}$ \\
\hline Itália & $\begin{array}{l}\text { Critérios para compras públicas sustentáveis, exigindo que os produtos tenham algum } \\
\text { tipo de rótulo ambiental e/ou certificação de produção controlada; } \\
\text { Preferência por empresas que aderem a programas de gestão ambiental reconhecidos, } \\
\text { como o ISO 14001; } \\
\text { Nos critérios de seleção de fornecedores, considerou as empresas com práticas de } \\
\text { auditoria social, que adotam compras verdes, têm código de ética dos fornecedores e } \\
\text { interno, que adotam sistema de saúde e segurança, que mantêm boas relações } \\
\text { comunitárias e adotam política trabalhista. }\end{array}$ \\
\hline
\end{tabular}

\begin{tabular}{ll}
\hline Japão & $\begin{array}{l}\text { Governos e indústria criaram uma organização que promove o consumo sustentável, } \\
\text { com treinamentos, publicações e desenvolvimento de catálogo de compras sustentáveis } \\
\text { na internet. }\end{array}$
\end{tabular}
na internet.

\begin{tabular}{|c|c|}
\hline México & $\begin{array}{l}\text { O governo federal mexicano faz parte de um grupo de compras públicas verdes em } \\
\text { relação ao acordo de livre-comércio do Nafta (North American Free Trade Agreement- } \\
\text { Acordo de Livre Comércio da América do Norte); } \\
\text { Programa de gestão ambiental pública, com capacitação de funcionários, economia de } \\
\text { energia, reciclagem, entre outros; } \\
\text { Inclusão de princípios de licitação sustentável na Lei de Licitação do México, com } \\
\text { exigência de eficiência energética e de economia de água nos contratos e aquisições do } \\
\text { governo. }\end{array}$ \\
\hline Noruega & $\begin{array}{l}\text { Criação de um decreto em 2001, que determina medidas de licitação sustentável. Por } \\
\text { esse decreto, os noruegueses devem considerar os impactos ambientais relativos à } \\
\text { exploração de recursos naturais e despejos finais. }\end{array}$ \\
\hline $\begin{array}{l}\text { Países } \\
\text { Baixos }\end{array}$ & $\begin{array}{l}\text { Criação, em 1999, de website de referência para as compras públicas sustentáveis, } \\
\text { incluindo especificações para compras e contratações de } 30 \text { categorias de produtos, } \\
\text { serviços e obras. }\end{array}$ \\
\hline $\begin{array}{l}\text { Reino } \\
\text { Unido }\end{array}$ & $\begin{array}{l}\text { Treinamento dos funcionários que fazem as compras públicas para promoção das } \\
\text { licitações sustentáveis; } \\
\text { Criação de força-tarefa para promoção da licitação sustentável, no âmbito da estratégia } \\
\text { de desenvolvimento sustentável, a partir de março de } 2005 \text {. }\end{array}$ \\
\hline Suécia & $\begin{array}{l}\text { Iniciou o programa de licitação sustentável em } 2001 \text {, com criação de uma entidade } \\
\text { constituída de empresas e instituições públicas, que define as prioridades para compras } \\
\text { sustentáveis, baseando suas decisões em estudos científicos de ciclo de vida e análises } \\
\text { econômicas para construir critérios e indicadores de sustentabilidade de produtos e } \\
\text { serviços. Os resultados dos estudos são publicados na internet para que a consulta } \\
\text { pública possa identificar os possíveis problemas, tornando o processo rápido e barato. }\end{array}$ \\
\hline
\end{tabular}

Fonte: Adaptado de BIDERMAN et al. (2006).

A partir da análise de tais experiências, é possível se observar ideias, que vistas de acordo com a realidade e necessidades do Brasil, podem ajudar a melhorar os aspectos da licitação sustentável brasileira. No caso da Suécia, por exemplo, a definição das prioridades para compras sustentáveis é feita de acordo com estudos científicos de ciclos de vida de produtos e análise econômica para construção de critérios e indicadores de sustentabilidade de produtos e serviços. Essa ação parece ser interessante e bastante racional e poderia ser reproduzida no Brasil. 


\section{Conclusão}

O presente trabalho buscou examinar o papel do fator sustentabilidade nas licitações e contratos públicos. Os resultados da investigação revelaram que embora existam dificuldades em identificar e instituir critérios uniformes acerca da sustentabilidade para todas as formas de contratação pública, eles não podem deixar de ser exigidos pela Administração, na medida em que a promoção ao desenvolvimento sustentável é obrigação constitucional do Poder Público.

Na prática, o que se vê, no entanto, é que, em muitos casos, a Administração não está preparada para realizar procedimentos licitatórios sustentáveis, em razão da sua deficiência em identificar, na fase de planejamento, o impacto ambiental do objeto a ser executado. Dessa forma, ela acaba por deixar de exigir no edital de licitação, requisitos para conservação e proteção do meio ambiente, necessários para o cumprimento do objeto com respeito às normas ambientais.

No caso da construção civil, observou-se que antes de realizar qualquer obra é de bom senso pensar nas opções disponíveis para atender à necessidade de construção com a escolha da alternativa que provoque o menor prejuízo ambiental possível, sendo que é importante considerar que os aspectos ambientais possuem reflexos econômicos e sociais. Ou seja, quando se pensa no meio ambiente, se pensa também, no bem estar da sociedade e que a preocupação ambiental pode estar aliada a maiores benefícios econômicos. Na construção civil, o uso racional de materiais, com redução da pressão de uso dos recursos naturais, é um exemplo da possibilidade de conciliar interesses econômicos com a consciência ambiental.

A importância do poder público em induzir transformações no mercado a partir do seu peso de intervenção na economia por força das compras e contratos que realiza é um fator crucial para que as licitações sustentáveis sejam vistas como uma forma eficiente de investimento na sustentabilidade, gerando benefícios sociais e econômicos, além das vantagens para a conservação e proteção do meio ambiente.

Do exposto, sugere-se que a Administração Pública, ainda que na ausência de critérios ambientais de julgamento de propostas, fixados por Lei, elabore parâmetros para exigir do particular, nos certames licitatórios, a realização de condutas ou a adoção de práticas sustentáveis compatíveis com o objeto licitado e o encargo a ser executado, dentro do chamado "bloco de legalidade".

Sugere-se também, que os fornecedores e empreiteiras que façam uso racional de recursos naturais e que exerçam ações de promoção social, tenham preferência ou exclusividade nas licitações, de acordo com critérios de sustentabilidade a serem considerados para habilitar os participantes de um certame licitatório e contribuir na definição da posição final dos participantes da disputa pelo objeto a ser licitado. E ainda podem ser adotadas ações de outros países, como a definição das prioridades para compras sustentáveis ser feita de acordo com estudos científicos de ciclos de vida de produtos e análise econômica para construção de critérios e indicadores de sustentabilidade de produtos e serviços.

Como limitação, o trabalho não permitiu dialogar com os atores envolvidos no processo licitatório para ampliar informações. Recomenda-se que novas pesquisas, em especial de cunho quantitativo, possam aprofundar aspectos fundamentais sobre as licitações públicas, com a aplicação de questionários junto aos gestores públicos e às empresas de construção civil, buscando verificar a realidade vivenciada por esses atores. Ainda, estudos que possam verificar a influência da legislação em pequenos municípios, de realidades diferenciadas. 


\section{Referências}

ASSOCIATION FRANÇAISE DE NORMALISATION (AFNOR). SD 21000: Développement durable - Responsabilité sociétale des entreprises: guide pour la prise en compte des enjeux du développement durable dans la stratégie et le management de l'entreprise. Paris, 2003.

BACCI, D. C.; LANDIM, P. M. B.; ESTON, S. M. Aspectos e impactos ambientais de pedreira em área urbana. Rem: Revista Escola de Minas, v. 59, n. 1, p. 47-54, Ouro Preto, 2006.

BARBIERI, J. et al. Inovação e sustentabilidade: novos modelos e proposições. Revista de Administração de Empresas, v. 50, n. 2, p. 146-154, 2010.

BIDERMAN, R. et al. Guia de compras públicas sustentáveis: uso do poder de compra do governo para a promoção do desenvolvimento sustentável. São Paulo: CLEl European Secretariat $\mathrm{GmbH}, 2006$.

BLOWFIELD, M. Business and Sustainability. Oxford: Oxford University Press, 2013.

BRASIL. Constituição da República Federativa do Brasil, 1988.

Decreto 7.581 de 11 de outubro de 2011. Disponível em: <http://www.planalto.gov.br/ccivil_03/_ato2011-2014/2011/Decreto/D7581.htm>.Aces-so em: 30 jun. 2014.

Lei $n^{\circ} 10.257$ de 10 de julho de $2001 . \quad$ Disponível em: <http://www.planalto.gov.br/ccivil_03/leis/leis_2001/l10257.htm >. Acesso em: 24 nov. 2014.

Lei $n^{\circ} 12.462$ de 04 de agosto de 2011. Disponível em: <http://www.planalto.gov.br/ccivil_03/_ato2011-2014/2011/Lei/L12462.htm>. Acesso em: 30 jun. 2014.

Lei $n^{\circ} 6.938$ de 31 de agosto de 1981. Disponível em: <http://www.planalto.gov.br/ccivil_03/leis/l6938.htm>. Acesso em: 30 jun. 2014.

Lei 7.347 de 24 de julho de 1985. Disponível em: <http://www.planalto.gov.br/ccivil_03/leis/l7347orig.htm>. Acesso em: 30 jun. 2014.

Lei $n^{\circ} 8.666$ de 21 de junho de 1993. Disponível em: $\overline{<\mathrm{http} / / / w w w . p l a n a l t o . g o v . b r / c c v i l[03 / L e i s / L 8666 c o n s . h t m>. ~ A c e s s o ~ e m: ~} 30$ jun. 2014

Ministério do Meio Ambiente. Resolução CONAMA no 01, de 23 de janeiro de 1986. Disponível em: <http://www.mma.gov.br/port/conama/legiabre.cfm?codlegi=23>.Acesso em: jun. 2014.

Ministério do Planejamento, Orçamento e Gestão (MPOG) e Governos Locais pela Sustentabilidade (ICLEI). Guia de compras públicas sustentáveis, 2010. Disponível em: <http://cpsustentaveis.planejamento.gov.br/wp-content/uploads/2010/06/Cartilha.pdf> Acesso em: 25 nov. 2014.

DALY, Herman E. Introduction to the steady-state economy. In: DALY, H. E. (org.). Economics, Ecology, Ethics. São Francisco, Freeman, pp. 1-31.1980.

DEACON, Robert T. et al. Research trends and opportunities in environmental and natural resource economics. Environmental and Resource Economics, v. 11, n. 3-4, p. 383-397, 1998.

FISHER, Anthony C. Resource and environmental economics. CUP Archive, 1981.

FREITAS, J. Princípio da sustentabilidade: licitações e a redefinição da proposta mais vantajosa. Revista do Direito UNISC, v. 2, n.38, p. 74-94, Santa Cruz do Sul, 2012. 
KUSTER, C., et al. Projeto Tapera. Trabalho de Conclusão do Módulo de Monitoramento Ambiental do Curso Técnico de Meio Ambiente. CEFET. Florianópolis, 2007.

MARCONI, M. A.; LAKATOS, E. M. Técnica de pesquisa, planejamento e execução de pesquisas, amostragem elaboração, análise e interpretação de dados. São Paulo: Atlas, 2007.

OLIVEIRA, L. R.; MARTINS, E. F.; LIMA, G. B. A. Evolução do conceito de sustentabilidade: um ensaio bibliométrico. Relatórios de Pesquisa em Engenharia de Produção, v. 10, n. 4, p. 1-17, Rio de Janeiro, 2010.

PEARCE, David W.; TURNER, R. Kerry. Economics of natural resources and the environment. JHU Press, 1990.

PEERMAN, E. et al. Natural resource and environmental economics. 2.ed. Essex, Engl.: Longman, 1999.

PEREIRA, S. S.; CURI, R. C. Meio ambiente, impacto ambiental e desenvolvimento sustentável: conceituações teóricas sobre o despertar da consciência ambiental. Revista de Administração, Contabilidade e Sustentabilidade, v. 2, n. 4, p. 35-57, Campina Grande, 2012.

REDCLIFT, M. Sustainable development: exploring the contradictions. London: Routledge, 1992.

ROMEIRO, A. R.; MAIA, A. G. Avaliação de custos e benefícios ambientais. Cadernos ENAP, v. 1, n. 35, Brasília, 2011.

SACHS, I. Rumo à ecossocioeconomia: teoria e prática do desenvolvimento. São Paulo: Cortez, 2007.

SÁNCHEZ, L. E. Avaliação de impacto ambiental: conceitos e métodos. São Paulo: Oficina de Textos, 2008.

SOARES, B. E. C. et al. Desenvolvimento sustentado e consciência ambiental: natureza, sociedade e racionalidade. Ciências \& Cognição, v. 2, p. 42-49, Rio de Janeiro, 2004.

SPADOTTO, A. et al. Impactos ambientais causados pela construção civil. Revista Unoesc \& Ciência, v. 2, n. 2, p. 173-180, Joaçaba, 2011.

TIETENBERG, T. H.; LEWIS, L. Environmental and natural resource economics. Routledge, 2016.

TORRES, R. L. Licitações sustentáveis: sua importância e seu amparo constitucional e legal. Interesse Público - IP, ano 14, v. 71, p. 219-241, Belo Horizonte, 2012.

VALENTE, M. A. L. Marco legal das licitações e compras sustentáveis na Administração Pública. Brasília: Biblioteca Digital Câmara, 2011.

VEIGA, J. E. Desenvolvimento sustentável: o desafio do século XXI. Editora Garamond, 2005.

VERGARA, S. C. Projetos e relatórios de pesquisa em administração. São Paulo: Atlas, 2010.

WORLD COMISSION ON ENVIROMENMENT AND DEVELOPMENT - CMMD. Our common future. Oxford: Oxford University Press, 1988. 